\title{
Structural Breaks in the Real Exchange Rate and Real Interest Rate Relationship*
}

\author{
Joseph P. Byrne and Jun Nagayasu \\ $30^{\text {th }}$ October 2008
}

\begin{abstract}
:
In this paper we empirically examine the relationship between the real exchange rate and real interest rate differentials using recent econometric methods robust to potential structural breaks. Generally, our study provides evidence of this relationship in the long-run context. More specifically, we first focus on the UK-US relationship, and interestingly find limited evidence of this long-run relationship using traditional methods. But when an approach robust to endogenously determined structural breaks is employed, we find evidence that the real interest rate differential is an important determinant of the real exchange rate. Secondly, in order to investigate the relevance of structural shifts in a more global context, we carry out multiple country analysis. While providing evidence of this long-run relationship, European data suggest that the presence of structural breaks is not very common across countries and is indeed country-specific.
\end{abstract}

Keywords: Real exchange rate; real interest rate differential; nonstationarity; endogenously determined structural breaks; trace tests

JEL Classification: F31

Filename: JoeJun_Oct30_2008_GFJ

\footnotetext{
* Byrne: Department of Economics, University of Glasgow, Glasgow, G12 8RT, UK, E-mail: $<$ j.byrne@lbss.gla.ac.uk>. Nagayasu (Corresponding author): Graduate School of Systems and Information Engineering, University of Tsukuba, 1-1-1 Tennodai, Tsukuba, Ibaraki 305-8573 Japan, E-mail: <nagayasu@sk.tsukuba.ac.jp>. We would like to thank Manuchehr Shahrokhi (editor) and anonymous referees for useful comments. However, all errors are ours. The second author received financial support from the Murata Science Foundation.
} 


\section{Introduction}

A long-run relationship between the real exchange rates and real interest rate differential can be obtained using the conventional equilibrium conditions often used in the international finance literature. In particular, Uncovered Interest Parity (UIP) and the Fisher Hypothesis can be considered as the starting point of a theoretical link between the real exchange rates and interest rates. ${ }^{1}$ A number of studies have attempted to uncover evidence of an equilibrium relation based on such an approach and provided mixed results (e.g., Campbell and Clarida 1987, Meese and Rogoff 1988 and Edison and Pauls 1993).

A major concern among researchers is the low power of statistical tests to detect equilibrium relationships in international finance. Since at least Perron (1989), it has been recognized that incorrectly modelling economic variables as linear, when they are subject to substantial, unusual and infrequent shocks, can affect the usefulness of statistical results. In particular, conventional unit root and cointegration tests are biased towards the null when there is a structural break in a time series. Thus some recent evidence has highlighted the importance of testing for breaks or non-linearities when considering the real exchange rate-interest rate relationship. ${ }^{2}$ For example, Nakagawa (2002) emphasizes non-linearities in the relationship between real exchange rates and real interest rates. Additionally accounting for changing economic regimes and using a long history of data (1921-2002), Kanas (2005) uncovers a relationship between the US/UK real exchange rate and the real interest rate differential.

\footnotetext{
${ }^{1}$ Optimising models of exchange rate determination are also suggestive of a link. See Obstfeld and Rogoff (1996).

${ }^{2}$ Baxter (1994) also fails to find evidence of a statistical link between real exchange rates and real interest rates at the high frequency level, although in a more positive vein of research finds more
} 
In this paper we empirically examine whether a long-run equilibrium relationship exists between the real exchange rate and real interest rate differential. Therefore, in contrast to Nakagawa (2002) and Kanas (2005), we emphasize the potential nonstationary characteristic of the data, since there is widespread evidence of a nonstationary real exchange rate, which is the failure of PPP, and a nonstationary difference between the real interest rates across countries (Meese and Rogoff, 1988, and Edison and Pauls, 1993). For example, Kanas uses the Markov-Switching Vector Auto-Regressive model although the methodology is primarily for stationary data and additionally presents evidence of a nonstationary real exchange rate. In a similar view to our paper, Edison and Melick (1999) also consider the equilibrium relationship between the real exchange rate and real interest rate differential. They emphasize potential nonstationarity and also adjust for potential structural breaks by including shift dummies. Such an approach leads to evidence in favour of the exchange rate interest differential relation. However, the date of these dummies is not endogenously determined and the Johansen (1998) Trace test requires adjusted critical values in the presence of structural shifts (see Lütkepohl, 2004).

This paper is laid out as follows. Section 2 considers the theory related to the real exchange rate-interest rate relationship. Section 3 considers our empirical methodology. Section 4 considers the data used in this study, and presents and interprets our empirical results. Section 5 extends the analysis to other industrial countries using single country and panel data methods in order to see if structural breaks are common phenomena across countries. This paper ends with Section 6 that summarizes our findings.

evidence at the low frequency or business cycle level. 
In short, using multiple-equation estimation methods robust to potential nonstationarity, we uncover results consistent with the previous literature in that there is no evidence of cointegration in the UK data when traditional linear methods are employed. However, adopting an approach set out by Saikkonen and Lütkepohl $(2000,2002)$ and Lanne, Lütkepohl and Saikkonen $(2002,2003)$ and utilizing more powerful cointegration tests which are additionally robust to the possibility of endogenously determined structural breaks, we find evidence of a long-run relation. However, we caution the significance of structural breaks in a global market. Our multiple country analysis suggests that while providing evidence of this long-run relationship, the presence of structural breaks is not very common across industrial countries and thus is indeed country-specific.

\section{Theoretical Model}

In deriving an operational equation for the relationship between the real exchange rate and real interest rates, we essentially follow Edison and Pauls (1993). ${ }^{3}$ The two main components of this model are UIP and the Fisher parity condition. We set out each of these in turn before defining an estimable equation. Firstly, we define the real exchange rate $\left(q_{t}\right)$ as follows:

$$
q_{t}=s_{t}-p_{t}+p_{t}^{*}
$$

where $s_{t}$ is the natural logarithm of the spot nominal exchange rate (domestic currency

\footnotetext{
${ }^{3}$ An alternative approach would be to adopt Dornbusch's (1976) sticky price model, as used for example by Nakagawa (2002). However, this approach assumes a stationary real exchange rate, which is inconsistent with the approach we adopt in the empirical section of this paper, since we find evidence that the real exchange rate is nonstationary, even once we account for possible structural breaks. In setting out our model we illustrate that the Dornbusch sticky price model is not a necessary component
} 
units per unit of foreign currency), $\quad p_{t}$ and $p_{t}^{*}$ are the logarithm of domestic and foreign price indexes, respectively. The UIP asserts that with open capital markets and perfect foresight, expected changes in the nominal exchange rate are equal to the differential in the nominal interest rate. When investors are not risk neutral, UIP can be extended to include the risk premium.

$$
E_{t}\left(s_{t+1}-s_{t}\right)=i_{t}-i_{t}^{*}+u_{t}
$$

where $i_{t}$ and $i_{t}^{*}$ are domestic and foreign nominal interest rates, $E_{t} s_{t+1}$ is the current period expectations of the next period exchange rate, and $u_{t}$ is the exchange risk premium. Consequently substituting out the expected nominal exchange rate we have

$$
E_{t} q_{t+1}-E_{t} p_{t+1}^{*}+E_{t} p_{t+1}-s_{t}=i_{t}-i_{t}^{*}+u_{t}
$$

Additionally we assume that the expected change in inflation is as follows

$$
\begin{aligned}
& E_{t} \Delta p_{t+1}=E_{t} p_{t+1}-p_{t} \\
& E_{t} \Delta p_{t+1}^{*}=E_{t} p_{t+1}^{*}-p_{t}^{*}
\end{aligned}
$$

Furthermore, the ex-ante 1-period real interest rate is equal to the nominal interest rate minus expected inflation:

$$
\begin{gathered}
r_{t}=i_{t}-E_{t} \Delta p_{t+1} \\
r_{t}^{*}=i_{t}^{*}-E_{t} \Delta p_{t+1}^{*}
\end{gathered}
$$

From these equations, we can obtain the following expression.

$$
E_{t} q_{t+1}-\left(E_{t} \Delta p_{t+1}^{*}+p_{t}^{*}\right)+\left(E_{t} \Delta p_{t+1}+p_{t}\right)-s_{t}=\left(r_{t}+E_{t} \Delta p_{t+1}\right)-\left(r_{t}^{*}+E_{t} \Delta p_{t+1}^{*}\right)+u_{t}
$$

Finally, we obtain an expression for the expected changes in the real exchange rate

of the parity condition under consideration. 


$$
\begin{aligned}
& E_{t} q_{t+1}-p_{t}^{*}+p_{t}-s_{t}=r_{t}-r_{t}^{*}+u_{t} \\
& E_{t} q_{t+1}-q_{t}=r_{t}-r_{t}^{*}+u_{t} \\
& q_{t}=-r_{t}+r_{t}^{*}+E_{t} q_{t+1}+u_{t}
\end{aligned}
$$

One operational problem in equation (11) is that the expected values of the real exchange rate are not readily available to researchers. Several proxies have been previously considered, for example, Meese and Rogoff (1988) suggest the cumulative trade balances and a constant. Alternatively time dependence in the expected real exchange rate may be modelled by a shift dummy if the equilibrium does not change often. In initially laying out the model here for simplicity we assume the expected real exchange rate is constant, as also considered by Meese and Rogoff (1988), Edison and Pauls (1993) and Baxter (1994). Our failure to support the long-run relationship calls for further investigation about the assumption related to the expected real exchange rate. Then, we obtain from equation (11). ${ }^{4}$

$$
q_{t}=\alpha r_{t}+\alpha^{*} r_{t}^{*}+\text { constant }+u_{t}
$$

The time-varying risk premium, $u_{t}$, is an unobservable component in this equation and is assumed to be stationary. Equation (12) serves as the basis of our estimation approach. The main suggestion is that the real interest rate differential is negatively related to the real exchange rate of the domestic currency (i.e. $\alpha<0$ and $\alpha^{*}>0$ ).

\footnotetext{
${ }^{4}$ One could consider imposing homogeneity or symmetric restrictions on parameters in equation (12).
} 


\section{Empirical Methodology}

A number of methodological points have been emphasized in the empirical literature on exchange rate modelling which also influences our particular approach. These include: potential nonstationarity of data and its implications for identifying long-run relations; a concern with the low power of test statistics (i.e. inability to reject a false null hypothesis of unit root or no cointegration) and attempts to improve the power properties of our test statistics by increasing the time span or the cross sectional coverage of our data set; and finally an issue with structure breaks in time series models. We shall briefly review each of these issues in turn.

The first question is related to potential data nonstationarity, for example the real exchange rate, which necessitates empirical tests and estimators robust to the challenges that are raised. Empirical studies have often utilised single-equation or system-of-equation cointegration techniques to uncover evidence of equilibrium relationships and to provide reliable long-run estimators. In terms of the real exchange rate-yield differential symbiosis, single equation approaches include Campbell and Clarida (1987), Meese and Rogoff (1988) and Edison and Pauls (1993). However, failure to uncover evidence may be due to the power of statistical tests, first raised in a univariate context by De Jong et al. (1992).

Due to a concern with the low power of our test statistics, two veins of literature evolved when considering particular hypotheses in the exchange rate literature: expanding the sample span by expanding the time series or the cross sectional dimension of data sets. Panel data sets which have both time series and cross sectional dimensions have been 
utilised to examine the exchange rate interest rate relationship. For example, a panel approach to estimating the relationship between real exchange rates and real interest rates is adopted by Chortareas and Driver (2001). They find relatively successful evidence in favour of the exchange rate-interest differential relation although this is focused on the bilateral relationships between small open economies and not the G7. MacDonald and Nagayasu (2000) also use panel cointegration methods and find more evidence in favour of the real exchange rate-interest rate link. However, there may be important differences in estimated coefficients across cross sections of the panel which may induce bias in dynamic estimation (see Pesaran and Smith, 1995).

Alternatively Campbell and Perron (1991) propose that extending the span of the data set would be one way to improve the power of statistical tests. This has resulted in data sets which extend beyond the post-Bretton Woods period of floating exchange rates (see for example, Lothian and Taylor, 1996). However, Campbell and Perron (1991) also suggest that extending the time dimension used in empirical studies can lead to problems with structural breaks and hence further problems with the power of these tests. This is the view point elicited by Perron (1989) such that when there are structural breaks in a univariate time series this may suggest that the series is nonstationary. Likewise, for a cointegrating vector, to the extent that there are breaks in the equilibrium relationship this may result in tests for no cointegration accepting the null hypothesis that there is not an equilibrium relationship when in fact one exists. Edison and Melick (1999) suggest breaks in the real exchange rate-real interest rate relationship are important, when using system-of-equation

statistically due to measurement errors which likely exist in any empirical research. 
tests for cointegration. ${ }^{5}$ Recently, Saikkonen, and Lütkepohl $(2000,2002)$ have proposed a systems approach to testing for equilibrium relationships between variables which is based on a vector autoregressive approach with structural shifts and also utilises Generalized Least Square (GLS) detrending. ${ }^{6}$ We discuss this approach shortly.

\section{UK-US Empirical Evidence}

\subsection{Data}

Data are obtained from the International Monetary Fund's International Financial Statistics (IFS). ${ }^{7}$ Our sample period covers monthly data from 1973M1 to 2005M5. The UK pound-US dollar real exchange rates $\left(q_{t}\right)$, as set out in equation (1), is in logarithmic form based on end-of-period rates (IFS line AE). Real interest rates $\left(r_{t}\right)$ are calculated by subtracting expected inflation from the short run interest rate (Money Market Rates, IFS line 60b) expected nominal interest rates (i.e. $r_{t}=i_{t}-E_{t} \Delta p_{t+1}$ ). We have two measures of expected inflation, ex ante $\left(\Delta p_{t+1}\right)$ and ex post $\left(\Delta p_{t}\right)$ inflation which are based on the realised consumer price index (CPI, IFS line 64). ${ }^{8}$ The UK is the domestic economy $\left(r_{t}\right)$ whilst the US is the foreign country $\left(r_{t}^{*}\right)$.

\footnotetext{
${ }^{5}$ Importantly Edison and Melick (1999) do not use nonstandard critical values when presenting their results which we discuss further below.

${ }^{6}$ See also Elliott et al. (1996) for an examination of the improved power properties of nonstationary tests which utilize GLS detrending.

${ }^{7}$ This was obtained from the Economic and Social Data Service <www.esds.ac.uk>.

${ }^{8}$ Meese and Rogoff (1988) also use actual inflation rates.
} 


\subsection{Potential Data Nonstationarity and Structural Breaks}

To initially establish that we are dealing with nonstationary time series, we implement two types of unit root tests: the Augmented Dickey-Fuller test (see Dickey and Fuller, 1979) and Saikkonen and Lütkepohl (2002) test, henceforth known as S\&L. Among several other tests, $S \& L$ propose the unit root test with a simple shift dummy. The basic equation for this test without linear trend can be summarized using the following equation for a time series $y_{t}$

$$
y_{t}=\mu_{0}+f_{t}(\theta)^{\prime} \gamma+x_{t}
$$

The error term, $x_{t}$, follows a finite-order $\operatorname{AR}(p)$ representation $\alpha(L)(1-\rho L) x_{t}=u_{t}$ where $\alpha(L)=1-\alpha_{1} L-\ldots-\alpha_{p-1} L^{p-1}$ and $u_{t} \sim$ iid $\left(0, \sigma^{2}\right)$. The parameter, $\rho$, is, $-1<\rho \leq 1$ and $\rho=1$ indicates the unit root process. The shift function, $f_{t}(\theta)$, will be defined shortly. This equation in first difference form is:

$$
\Delta y_{t}=\Delta f_{t}(\theta)^{\prime} \gamma+v_{t}
$$

where $v_{t}=\alpha(L)^{-1} u_{t}$. Thus, the estimation for the parameter, $\eta=\left(\mu 0, \gamma^{\prime}\right)^{\prime}$, is conducted by minimizing the generalized sum of squared errors of this equation, which alternatively can be expressed as:

$$
Q_{p}(\alpha, \theta)=(Y-Z(\theta) \eta)^{\prime} \operatorname{Cov}\left(V / \sigma_{u}^{2}\right)^{-1}(Y-Z(\theta) \eta)
$$

where $Y=\left[y_{1}, \Delta y_{2}, \ldots, \Delta y_{T}\right]^{\prime}$ and $Z=\left[Z_{1}: Z_{2}: Z_{3}\right]$ where $Z_{1}=[1,0, \ldots, 0]^{\prime}$, $Z_{2}=[1,1, \ldots, 1]^{\prime}$, and $Z_{3}=\left[f_{1}(\theta), \Delta f_{2}(\theta), \ldots, \Delta f_{T}(\theta)\right]^{\prime}$, and $V=\left[v_{1}, v_{2}, \ldots, v_{T}\right]^{\prime}$.

So far little is said about the shift function. This paper focuses on a case where a 
shift date, $T_{B}$, can be characterized as the shift dummy, $d_{t}$, and has the following form:

$$
f_{t}(\theta)^{\prime} \equiv d t= \begin{cases}0 & t<T_{B} \\ 1 & t \geq T_{B}\end{cases}
$$

Obviously, when the shift date is known, we can readily estimate equation (13). Lanne, Lütkepohl, and Saikkonen (2002) suggests that the deterministic term be estimated by the GLS method, and then apply the ADF type test to the adjusted data that can be obtained by subtracting the deterministic component from the original data. However, this requires a priori knowledge of break dates. Thus, Lanne, Lütkepohl, and Saikkonen (2003) propose a procedure given the lag order $p$. Their recommendation is consistent with minimization of $Q_{p}$ and the shift date is determined by the one corresponding to the smallest value of $Q_{p}$. Like the $\mathrm{ADF}$, a statistic for this test does not possess a standard distribution, hence critical values provided by Lanne, Lütkepohl, and Saikkonen (2002) are used in order to evaluate the null hypothesis of the unit root.

The results from the unit root tests are summarized in Table 1 where the appropriate lag length is determined by the Akaike Information Criterion (AIC). ${ }^{9}$ The ADF unit root tests suggest that we cannot reject the null of nonstationarity for the real exchange rate and ex ante and ex post real interest rates for the UK and US. This is consistent with evidence in Edison and Pauls (1993) and Chortareas and Driver (2001). ${ }^{10}$ For the S\&L unit root tests, we find evidence of nonstationarity for the real exchange rate and US real interest rates.

\footnotetext{
${ }^{9}$ Since the objective of research at this stage is to construct the general model, the AIC is used rather than others such as the Schwarz-Bayesian Information Criterion as suggested by Lanne, Lütkepohl and Saikkonen (2002).

${ }^{10}$ The overall conclusion from the S\&L test is consistent with that from Perron's test (1997), which also takes into account unknown regime shifts.
} 
However, there is evidence of stationarity for UK real interest rates. The nonstationarity of at least two variables, the real exchange rate and the US interest rate, ensures that the long-run relationship in equation (12) is not necessarily unbalanced.

Table 1 here

Regime shift dates obtained from the S\&L test are also reported in Table 1. For the real exchange rate, the shift dates are 1985M3 which coincides with the end of the strong dollar in the early 1980s. That was the period when the Plaza Accord was made in New York and whereby G5 member countries agreed to strengthen the dollar in order to combat US current account deficits. For the UK interest rates the endogenously determined break dates are 1979M7 for ex ante inflation and 1979M8 for ex post inflation, which coincides with a new monetary policy regime in the UK and the Thatcher Government. The break date for the US interest rate is $1980 \mathrm{M} 12$ and $1980 \mathrm{M} 7$, for ex ante and ex post inflation respectively, which again coincides with a change in US monetary policy.

Given our primary interest in modelling the real exchange rate, the subsequent part of this paper considers a possible regime shift in the equilibrium rate in 1985M3 for both systems (i.e. with either ex ante or ex post measures of the real interest rate). Thus our shift dummy can be defined as for and otherwise. It should be noted that the introduction of this dummy in the multivariate setting is also supported by Bai, Lumsdaine and Stock (1998) Sup-W and Exp-W tests, which are a statistical method for detecting and identifying common structural breaks in the multivariate time-series (VAR). The results from this test show the presence of structural shift in 1985M5 with a 90 percent confidence interval of 
1983-86. ${ }^{11}$ Therefore, we retain $1985 \mathrm{M} 3$ as our break date in the subsequent analysis, since this is well within this confidence interval, and also coincides with the end of the prolonged appreciation of the dollar, and a period of sustained foreign exchange intervention by the Federal Reserve Bank of New York on the eve of the Plaza Agreement (see Bordo and Schwarz 1990).

Finally, in order to ensure that our exchange rate contains at least one statistically significant structural shift, we implement multiple regime shift tests developed by Bai and Perron (1998). Amongst the tests they proposed, this paper employs so-called double maximum tests (UD max and WD max tests) which examine the null hypothesis of no regime shift against the alternative of the unknown number of shifts. In addition, the $\operatorname{SupF}(i+1 \mid i)$ test, which analyzes the null of $i$ regimes against $i+1$ regimes where $i=1$ to 4 , is employed in order to study the number of regime shifts in the exchange rate. Then, we find evidence of at least one shift according to the double maximum tests and the existence of only one shift in the data from the SupF test (Table 2).

Table 2 here

\subsection{Evidence of Cointegration}

Given the evidence in the previous section suggesting that our data are nonstationary, we analyse the possibility of a long-run relationship between the real exchange rate and real interest rates using nonstationary methods. In particular, we employ three cointegration tests: the Johansen $(1988,1995)$ and the Saikkonen and Lütkepohl

\footnotetext{
${ }^{11}$ However, this result should be interpreted with caution since there is a possibility that our data in the VAR may not be stationary. We have also investigated possible shifts in the VAR using the first difference of the data. However, we failed to obtain the results because of the singularity problem.
} 
(2000) Trace tests with and without structural breaks. The Johansen test is the standard approach to test for cointegration within a system of equations. The Johansen's Likelihood Ratio (LR) statistics are non-standard under the null, and are dependent on the size of $K-r$ (where $K$ is the number of variables and $r$ is the number of cointegrating vectors under the null hypothesis) and the composition of deterministic terms. We focus on the more conventional Trace test statistic.

$$
L R_{\text {Trace }}(r)=-T \sum_{j=r+1}^{K} \log \left(1-\lambda_{j}\right)
$$

and $\lambda_{j}$ are the smallest eigenvalues of the corresponding determinant equation and $T$ is the time span. While Johansen (1995) provides critical values for this test, including the shift dummy in the standard test requires a computation of the distribution for the statistics that should differ from the one provided by Johansen. In particular, Edison and Melick (1999) use a shift dummy within the Johansen-type approach and find greater evidence of the real exchange rate-real interest rate yield differential nexus. However, they do not make allowance for the non-standard distribution of their statistics when there is a shift dummy. ${ }^{12}$ We take account of these difficulties using the methods developed by Saikkonen and Lütkepohl (2000).

Consider the DGP of the data with shift dummy

$$
y_{t}=\mu_{0}+\delta d_{t}+x_{t}
$$

The shift dummy, $d_{t}$, has the same definition as before, and thus the shift date identified in the unit root test is used for the cointegration study. Then, a VECM can be

\footnotetext{
${ }^{12}$ See Lütkepohl (2004) for a detailed discuss of these issues.
} 
expressed as:

$$
\Delta y_{t}=v+\Pi\left[\begin{array}{l}
y_{t-1} \\
d_{t-1}
\end{array}\right]+\sum_{j=1}^{p-1} \Gamma_{j} \Delta y_{t-1}+\sum_{j=0}^{p-1} \gamma_{j} \Delta d_{t-j}+u_{t}
$$

where $v=-\Pi \mu_{0}$ and $\Pi=\alpha\left[\beta^{\prime}: \theta\right]$, where $\theta=-\beta^{\prime} \delta$.

Table 3 here

Firstly we present results based on traditional methods which are consistent with much of the previous evidence from the literature. The results from the Johansen Trace test $(1988,1995)$ are shown in Table 3 . We incorporate a constant in the cointegrating vector. ${ }^{13}$ This model for both ex ante and ex post interest rates is consistent with little visual evidence of a deterministic trend in the exchange rate or interest rate data. Table 3 provides no evidence of cointegration in our system based on the Johansen Trace test, with $p$-values from Trenkler (2004) at the five percent, or indeed ten percent, significance level. ${ }^{14}$

Table 4 here

The results from the S\&L Trace test without a shift dummy are reported in Table 4. We find somewhat more evidence of an equilibrium relationship between our three variables (i.e. at the seven percent significance level and twelve percent significance level for ex ante and ex post real interest rates to reject the null of no cointegration) than the Johansen test. However, there is no particularly strong evidence supporting the existence of

\footnotetext{
${ }^{13}$ There is little evidence that the real exchange rate has a tendency to proxy the behaviour of a deterministic trend, hence we exclude a time trend from the estimation.

${ }^{14}$ Additionally we experimented with bivariate relationships and found we could not reject the null hypothesis of no cointegration at the five percent level, following the approach of Johansen and Juselius (1992). This was also the case with the S\&L Trace tests with and without a dummy. Wu and Fountas (2000) test real interest rate parity using cointegration methods that allow for structural breaks and uncover mixed evidence of real interest rate convergence against the US. In contrast to our system of equations approach, Wu and Fountas use single equation methods.
} 
the long-run relationship under consideration. Therefore, a shift dummy may be important as suggested by the break in the real exchange rate from Table 1 and Table 2, the possibility of a shift in the equilibrium exchange rate (see the discussion in Section 1), the econometric theory of Perron (1989) and evidence in Edison and Melick (1999). ${ }^{15}$ The shift dummy was derived from the estimate of a break date for the real exchange rate from the estimated confidence interval, using the methods of Bai et al. (1998), and from Table 1 (i.e. 1985M3). Table 5 presents results for the S\&L test incorporating a shift. Unlike the standard Johansen test and also the uncorrected S\&L test, we find some evidence of cointegration between the real exchange rate and real interest rates for the ex ante real interest rate at the five percent level and for the ex post real interest rate at the six percent level. Thus, one of reasons for the poor performance of the real interest rate differential in explaining real exchange rate movements reported in previous studies is due to lack of consideration of regime shifts in the data. ${ }^{16}$

Table 5 here

\subsection{Estimating the Long-Run Relationship and Further Stability Tests}

Given evidence of cointegration, we can estimate our system in Vector Error Correction Model (VECM) and obtain long-run estimates for the real exchange rate-interest rate relationship. ${ }^{17}$ The VECM is conducted for real exchange rates based on one

\footnotetext{
${ }^{15}$ We incorporate one shift dummy in our empirical model, Hansen (2001) is of the view that once we consider more than one break the difference between stationary processes with breaks and non-stationary process becomes less worthwhile. This argument can be extended to cointegrating relationships.

${ }^{16} \mathrm{We}$ experimented with the inclusion of seasonal dummies and the results remained quantitatively the same.

${ }^{17}$ Here, in addition to the model with the ex ante real interest rate, we also consider the model with the ex post real interest rate since the $p$-value obtained from the S\&L test with a shift dummy (Table 5) is very close to five percent.
} 
cointegrating vector, and is estimated by the two-stage method proposed by S\&L. The first stage involves the estimation of the long-run relationship. Since only one cointegrating relationship is found from the $S \& L$ test, this relationship is obtained in the context of the single equation of the VECM which is estimated by the OLS, and is re-parameterized by normalizing the coefficient of the real exchange rate. The second stage involves the estimation of the whole system by the OLS which includes the cointegrating vector specified in the first stage as well as exogenous variables. Our estimates for the long-run cointegrating vector are presented in Table 6 . The appropriate lag orders are determined by the AIC, and $t$-statistics are reported in parenthesis.

Table 6 here

These estimates are consistent with the exchange rate interest differential relationship. The fact that the parameter for the exchange rate is normalized in the long run relationship makes intuitive sense; the real exchange rate is negatively (positively) correlated with UK (US) interest rates. ${ }^{18}$ This suggests that an increase in UK real interest rates is associated with a UK pound appreciation. In addition, the estimates for the cointegrating parameters now exhibit stability. The stability of their relationship has been checked using the recursive methods developed by Johansen (1995) and Hansen and Johansen (1999) (see Figures 1 and 2). Simple recursive estimates of eigenvalues are shown with a 95 percent confidence interval (Johansen, 1995) which can be used to examine the existence of cointegration over time. A more formal test of constancy of eigenvalues is the $\tau$ statistic (Hansen and Johansen, 1999) which analyzes the null of

\footnotetext{
${ }^{18}$ For the UK-US real exchange rate Chortareas and Driver (2001) find a coefficient of -0.021 on the
} 
model stability. Since these recursive eigenvalues and $\tau$ statistics are fairly stable and below the critical value respectively, we can conclude that our cointegrating parameters are reliable since they are based on a stable model.

\section{Multiple Country Evidence}

\subsection{Data}

To what extent are structural breaks significant in other pairs of countries? In this section we examine multi-country and panel evidence on the relationship between the real exchange rate and real interest rate differentials, taking account of potential structural breaks. Our sample of countries includes Austria, Belgium, Canada, Finland, France, Germany, Italy, Netherlands, Norway, Spain, Sweden and Switzerland. We use data between $1978 \mathrm{M} 1$ to $1998 \mathrm{M} 12$. This sample was chose to have a balanced data set, with a number of international currencies and the span was limited by the commencement of European Monetary Union. Our data source is the IFS. To construct the real exchange rate we use end of period bilateral exchange rate via-a-vis US dollar and also use the CPI. For the real interest rate we use money market interest rates and inflation based on the CPI. Here, we focus on the relationship between the real exchange rate and ex post real interest rate spread.

\subsection{Results}

In Table 7, we firstly examine whether we can reject the null hypothesis of nonstationarity for our multi-country time series, using the ADF and Saikkonen-Lütkepohl tests. Given that we consistently find evidence of nonstationarity in the real exchange rate

interest rate differential based on linear models and CPIs. 
and ex post real interest rate in Table 7 and a nonstationary US real interest rate (Table 1), it is appropriate to use nonstationary methods to approach this question. The weak evidence of stationarity provided for some series (i.e. three out of 48 tests) is consistent with a reasonable nominal size for such a large number of unit root tests. With regards to the location of structural breaks, many countries (i.e. Austria, Belgium, Germany, Netherlands and Spain) experienced a structural break in early 1991 probably reflecting the effects of Germany reunification. Italy, Sweden and Finland all experienced a structural break in the real exchange rate at the time of the 1992 ERM crisis.

Table 7 here

In Table 8, we consider whether there is evidence of a long-run relationship between the real exchange rate and relative real interest rates in our large sample of countries. Using the conventional Johansen test, we find evidence of a cointegrating relation for the majority of countries ( 9 out of 12 cases) at the 10 percent significance level. This result is more favorable to the real exchange rate-interest rate relationship than previous studies and is attributable to the recent economic and financial integration particularly in Europe. However, of the three cases where no cointegration is obtained, we could find a cointegration relationship on one occasion (Switzerland) when we take account of breaks using the S\&L test. This suggests that there is a degree of heterogeneity for our sample of countries over this particular sample period. The real exchange rate-interest rate spread relationship does not seem to hold in Austria and Netherland. This may be because these countries monetary conditions were closely aligned with Germany. Including the UK investigated in Section 4, we studied 13 European countries and could 
obtain a cointegrating relation in 11 countries. Thus our evidence seems to suggest the long-run relationship between the real interest rate and interest rates although the structural shift may not be a very prevailing phenomenon across countries.

Table 8 here

Indeed, when we utilised Westerlund (2006) panel LM test statistic which takes account of structural breaks in a panel framework, we rejected the null hypothesis of a cointegrating vector for all countries against a null hypothesis of no cointegrating vector for some countries. That is to say the test statistic (38.219 and 32.096 for Fully-Modified OLS and Dynamic OLS respectively) was greater than the 5 percent critical value of $1.64 .{ }^{19}$ In the light of Table 8, this rejection of homogeneous panel cointegration may well be due to heterogeneity in our sample of countries. In contrast UK Sterling may have a sizable concordance with the dollar for our sample period, while having pursued European integration for only a short period during the entire sample which subsequently failed in the ERM collapse (see Blake and Byrne, 2002).

In short, our multi-country analysis suggests that the real exchange rate-interest rate spread relationship can be viewed as a long-run equilibrium condition. This is confirmed by country-specific and panel data methods. While this condition holds in most industrial countries without consideration of structural breaks, they are important in some countries like Switzerland and the UK. Thus importance of structural breaks seems to be country-specific.

${ }_{19}$ We were unable to reject the null hypothesis of panel cointegration using Westerlund (2006) panel 


\section{Conclusion}

There has been substantial interest in international parity conditions in international finance, in particular, interest in whether there is a relationship between the bilateral real exchange rate and real interest rate differential. The findings of previous studies are mixed, but more consistent and supportive evidence is reported when structural breaks are taken into account. Breaks are important when using potential nonstationary data since standard tests may suggest that there is no equilibrium relationship. Due to problems with low power with existing test statistics, we utilize recent innovations in tests for cointegration which take account of breaks, in particular the methods of Saikkonen and Lütkepohl $(2000,2002)$.

We initially examine the UK/US data and confirm the results from the previous literature using linear methods of no evidence of a real exchange rate-real interest rate differential relation. However, once structural breaks are taken into account, we find much stronger evidence of an equilibrium relationship between the pound-dollar real exchange rate and the differential between UK and US real interest rates. For example, there is evidence of one cointegrating relationship, and the model has reasonably sized, reasonably signed and significant long-run parameters. These are important results, we believe, given the widespread practice of utilizing longer data sets which may potentially encompass different policy regimes and changes in economic structure.

However, the importance of structural breaks seems rather different among countries. In order to check the relevance of structural shifts in a more global context, we extended our study to include other industrial countries. Our country-specific and panel

LM test even when we allowed for up to three structural breaks. 
data studies show that while the exchange rate-interest rate relationship exists in most countries, the importance of structural breaks are less pronounced in additional (i.e., non-UK) countries since this relationship is supported even if structural breaks are not considered. Since most additional countries are European, our findings would appear to highlight one distinguishing feature of the British economy in Europe.

Finally, it should be note that our finding is based on the theoretical specification which is probably the most restrictive because the expected real exchange rate is assumed to be constant. The introduction of the time-varying expected rate, which we expect to move more in line with the actual rate, will probably provide stronger evidence of the relationship between the real exchange rate and interest rate spread. 


\section{References}

Bai, J., R. Lumsdaine, R. L., Stock, J. H., 1998, Testing for and dating common breaks in multivariate time series, Econometrica 65, 395-434.

Bai, J. and P. Perron, 1998, Estimating and testing linear models with multiple structural changes, Econometrica 66, 47-78.

Baxter, M., 1994. Real exchange rates and real interest rate differentials: Have we missed the business cycle relationship? Journal of Monetary Economics 33, 5-37.

Blake, A.P. and J.P. Byrne, 2002, Sterling, the euro and the dollar. National Institute Economic Review. \#181. July.

Bordo, M.D. and A.J. Schwarz, 1990, What has foreign exchange market intervention since the Plaza Agreement accomplished? NBER Working Paper \#3562.

Campbell, J.Y. and R.H. Clarida, 1987, The dollar and real interest rates, Carnegie Rochester Conference Series on Public Policy 27, 103-140.

Campbell, J. Y. and P. Perron, 1991, Pitfalls and opportunities: What macroeconomists should know about unit roots, in O.J. Blanchard and S. Fischer (eds.) NBER Macroeconomic Annual 1991, MIT Press.

Chortareas, G.E. and R.L. Driver, 2001, PPP and the real exchange rate--real interest rate differential revisited: Evidence from nonstationary panel data. Bank of England Working Paper \#138.

Davidson, R. and J. MacKinnon, 1993, Estimation and Inference in Econometrics. Oxford University Press, London.

De Jong, D. N., J.C. Nankervis, N.E. Savin and C.H. Whiteman, 1992, The power problems of unit root tests in time series with autoregressive errors, Journal of Econometrics 53, 323-343.

Dickey, D. A. and W.A. Fuller, 1979, Estimators for autoregressive time series with a unit root, Journal of the American Statistical Association 74, 427-431.

Dornbusch, R., 1976, Expectations and exchange rate dynamics, Journal of Political Economy 84, 1161-1176.

Edison, H. J. and W.R. Melick, 1999, Alternative approaches to real exchange rates and real interest rates: Three up and three down, International Journal of Finance and Economics 4, 93-111.

Edison, H. J. and B. D. Pauls, 1993, A re-assessment of the relationship between real exchange rates and real interest rates: 1974-1990, Journal of Monetary Economics 31, 165-187.

Elliott, G., T.J. Rothemborg and J.H. Stock, 1996, Efficient tests for an autoregressive unit root, Econometrica 64, 813-836.

Gelbard, X. and J. Nagayasu, 2004, Determinants of Angola's real exchange rate, 1992-2002, Developing Economies XLII(3), 392-404.

Gregory, A. W., J. M. Nason, and D. G. Watt, 1996, Testing for breaks in cointegrated relationships, Journal of Econometrics 71, 321-341.

Hansen, B. E., 2001, The new econometrics of structural change: Dating breaks in US labour productivity, Journal of Economic Perspectives 15, 117-128.

Hansen, H. and S. Johansen, 1999, Some tests for parameter constancy in cointegrated 
VAR-models, Econometrics Journal 2, 306-333.

Johansen, S., 1988, Statistical analysis of cointegrating vectors, Journal of Economic Dynamics and Control 12, 231-254.

Johansen, S. and K. Juselius, 1992, Testing structural hypotheses in a multivariate cointegration analysis of the PPP and the UIP for the UK, Journal of Econometrics 53, 211-44.

Johansen, S., 1995, Likelihood-based Inference in Cointegrated Vector Autoregressive Models. Oxford University Press, Oxford.

Kanas, A., 2005, Regime linkages in the US/UK real exchange rate-real interest rate differential relation, Journal of International Money and Finance 24, 257-274.

Lanne, M., H. Lütkepohl and P. Saikkonen, 2002, Comparison of unit root tests for time series with level shifts, Journal of Time Series Analysis 23, 667-685.

Lanne, M., H. Lütkepohl, P. Saikkonen, 2003, Test procedures for unit roots in time series with level shifts at unknown time, Oxford Bulletin of Economics and Statistics 65, 91-115.

Lothian, J. R. and M. P. Taylor, 1996, Real exchange rate behaviour: The recent float from the perspective of the past two centuries, Journal of Political Economy 104, 488-509.

Lütkepohl, H., 2004. Vector autoregressions and vector error corrections. In Lütkepohl, H. and M. Krätzig, Applied Time Series Econometrics, Cambridge University Press, Cambridge.

MacDonald, R., 1995, Long-run exchange rate modelling, IMF Staff Papers 42, 437-489.

MacDonald, R. and J. Nagayasu, 2000, The long-run relationship between real exchange rates and real interest rate differentials: A panel study, IMF Staff Papers 47, 116-28.

Meese, R. and K. Rogoff, 1988, Was it real? The exchange rate-interest differential relation over the modern floating rate-period, Journal of Finance 43, 933-948.

Nakagawa, H., 2002, Real exchange rates and real interest rate differentials: implications of nonlinear adjustment in real exchange rates, Journal of Monetary Economics 49, 629-649.

Narayan P.K., 2008, The purchasing power parity revisited: New evidence for 16

OECD countries from panel unit root tests with structural breaks, Journal of International Financial Markets, Institutions and Money 18, 137-146.

Obstfeld, M. and K. Rogoff, 1996, Foundations of International Macroeconomics. MIT Press Cambridge, Massachusetts.

Perron, P., 1989, The Great crash, the oil price shock, and the unit root hypothesis, Econometrica 57, 1361-401.

Perron, P., 1997, Further evidence on breaking trend fluctuations in macroeconomic variables, Journal of Econometrics 80, 355-85.

Pesaran, M. H. and R. Smith, 1995, Estimating long-run relationships from dynamic heterogeneous Panels, Journal of Econometrics 68, 79-113.

Rogoff, K., 1996, The purchasing power parity puzzle, Journal of Economic Literature 34, 647-68.

Saikkonen, P. and H. Lütkepohl, 2000, Testing for the cointegrating rank of a VAR process with structural shifts, Journal of Business and Economic Statistics 18, 451-464.

Saikkonen, P. and H. Lütkepohl, 2002, Testing for a unit root in a time series with a level 
shift at unknown time, Econometric Theory 18, 313-348.

Trenkler, C., 2004, Determining p-values for systems cointegration tests with a prior adjustment for deterministic terms, mimeo, Humbolt-Universität zu Berlin.

Westerlund, J., 2006, Testing for Panel Cointegration with Multiple Structural Breaks, Oxford Bulletin of Economics and Statistics 68, 101-132.

$\mathrm{Wu}, \mathrm{J}-\mathrm{L}$. and S. Fountas, 2000, Real interest rate parity under regime shifts and implications for monetary policy, The Manchester School 68, 685-700. 
Table 1: ADF and Saikkonen and Lütkepohl Unit Root Tests

\begin{tabular}{|c|c|c|c|}
\hline Test statistic & $\mathrm{ADF}$ & S\&L & Shift date \\
\hline$q$ & $-2.311(1)$ & $-2.460(1)$ & 1985M3 \\
\hline With ex ante infla & & & \\
\hline$r$ & $-2.549(12)$ & $-3.161(12)$ & 1979M7 \\
\hline$r^{*}$ & $-1.742(11)$ & $-1.410(11)$ & 1980M12 \\
\hline With ex post infla & & & \\
\hline$r$ & $-2.279(12)$ & $-3.656(12)$ & 1979M8 \\
\hline$r^{*}$ & $-1.826(12)$ & $-1.540(12)$ & 1980M7 \\
\hline $5 \%$ Critical value & -2.860 & -2.880 & \\
\hline
\end{tabular}


Table 2: Multiple Regime Shift (Bai-Perron) Test for the Real Exchange Rate

\begin{tabular}{l|lll}
\hline Tests & Statistics & \multicolumn{2}{l}{ Critical values } \\
\hline & & $5 \%$ & $10 \%$ \\
UD max test & 7.970 & 8.880 & 7.460 \\
WD max test $(5 \%)$ & 15.004 & 9.910 & -- \\
WD max test $(10 \%)$ & 13.872 & -- & 8.200 \\
Sup $(i+1 \mid i)$ test & & & \\
$i=1$ & 1.255 & 8.580 & 7.040 \\
$i=2$ & 3.338 & 10.130 & 8.510 \\
$i=3$ & 0.305 & 11.140 & 9.410 \\
$i=4$ & 0.016 & 11.830 & 10.040 \\
\hline
\end{tabular}

Notes: Sample period 1973M1 to 2005M5. The trimming weight of 0.15 is used for calculating the statistics. The heterogeneity and autocorrelation consistent residuals are obtained using Andrews method. The critical values are provided in Bai and Perron (1998). 
Table 3: Johansen Trace Tests

\begin{tabular}{l|llll}
\hline Null Hypothesis & $H_{0}: r=0$ & $H_{0}: r=1$ & $H_{0}: r=2$ & Lag \\
\hline With ex ante inflation & $31.86[0.109]$ & $11.59[0.495]$ & $5.37[0.255]$ & 12 \\
$q, r, r^{*}$ & $10.94[0.556]$ & $3.50[0.503]$ & -- & 12 \\
$r, r^{*}$ & $13.72[0.317]$ & $5.47[0.244]$ & -- & 12 \\
$q, r$ & $16.38[0.160]$ & $4.42[0.365]$ & -- & 12 \\
$q, r^{*}$ & & & & \\
With ex post inflation & $27.67[0.260]$ & $10.79[0.570]$ & $4.80[0.317]$ & 12 \\
$q, r, r^{*}$ & $9.15[0.724]$ & $2.67[0.650]$ & -- & 12 \\
$r, r^{*}$ & $12.76[0.392]$ & $4.67[0.333]$ & -- & 12 \\
$q, r$ & $14.31[0.275]$ & $4.32[0.379]$ & -- & 12 \\
$q, r^{*}$ &
\end{tabular}

Notes: Sample period 1973M1 to 2005M5. P-values are in square brackets [.] for the Johansen Trace test and are based on critical values from Johansen (1995). Lag lengths of the VARs are determined by the Akaike Information Criterion with a maximum of 12 lags. A constant is included in the cointegrating vector. 
Table 4: The Saikkonen and Lütkepohl Trace Test Without Regime Shifts

\begin{tabular}{l|llll}
\hline Null Hypothesis & $H_{0}: r=0$ & $H_{0}: r=1$ & $H_{0}: r=2$ & Lag \\
\hline With ex ante inflation & $23.20[0.066]$ & $5.37[0.522]$ & $0.31[0.638]$ & 12 \\
$q, r, r^{*}$ & $6.41[0.393]$ & $0.71[0.454]$ & -- & 12 \\
$r, r^{*}$ & $7.27[0.304]$ & $0.04[0.880]$ & -- & 12 \\
$q, r$ & $5.27[0.535]$ & $1.69[0.226]$ & -- & 12 \\
$q, r^{*}$ & & & & \\
With ex post inflation & $21.24[0.115]$ & $4.90[0.585]$ & $0.31[0.639]$ & 12 \\
$q, r, r^{*}$ & $3.72[0.749]$ & $1.55[0.249]$ & -- & 12 \\
$r, r^{*}$ & $6.74[0.357]$ & $0.03[0.910]$ & -- & 12 \\
$q, r$ & $5.25[0.538]$ & $1.40[0.276]$ & -- & 12 \\
$q, r^{*}$ & $05 . P-v a c$ &
\end{tabular}

Notes: Sample period 1973M1 to 2005M5. P-values are in square brackets [.] and are based on Trenkler (2004) which are in turn based on critical values for the Trace test from Saikkonen and Lütkepohl (2000). This test rejects the null hypothesis of $r=i$ where the $p$-value is less than 0.05 . Lag lengths are determined by the Akaike Information Criterion with a maximum of 12 lags. A constant is included in the cointegrating vector. 
Table 5: The Saikkonen and Lütkepohl Trace Test With Regime Shifts

\begin{tabular}{l|llll}
\hline Null Hypothesis & $H_{0}: r=0$ & $H_{0}: r=1$ & $H_{0}: r=2$ & Lag \\
\hline With ex ante inflation & $25.66[0.031]$ & $7.67[0.268]$ & $0.54[0.523]$ & 12 \\
$q, r, r^{*}, d 85 M 3$ & $8.18[0.226]$ & $0.37[0.607]$ & -- & 12 \\
$r, r^{*}, d 85 M 3$ & $11.92[0.057]$ & $0.95[0.379]$ & -- & 12 \\
$q, r, d 85 M 3$ & $11.45[0.069]$ & $3.40[0.077]$ & -- & 12 \\
$q, r^{*}, d 85 M 3$ & & & & 12 \\
With ex post inflation & $23.58[0.059]$ & $7.07[0.323]$ & $0.91[0.390]$ & 12 \\
$q, r, r^{*}, d 85 M 3$ & $5.24[0.539]$ & $1.01[0.362]$ & -- & 12 \\
$r, r^{*}, d 85 M 3$ & $10.26[0.108]$ & $1.24[0.308]$ & -- & 12 \\
$q, r, d 85 M 3$ & $10.94[0.084]$ & $5.63[0.021]$ & -- & \\
$q, r^{*}, d 85 M 3$ & & & \\
\hline
\end{tabular}

Notes: Sample period 1973M1 to 2005M5. P-values are in square brackets [.] and are based on Trenkler (2004) which are in turn based on critical values for the Trace test from Saikkonen and Lütkepohl (2000). This test rejects the null hypothesis of $r=i$ where the $p$-value is less than 0.05 . Lag lengths are determined by the Akaike Information Criterion with a maximum of 12 lags. D85M3is a shift dummy which is zero before $1985 \mathrm{M} 3$ and one thereafter. A constant is also included in the cointegrating vector. 
Table 6: Estimates of Cointegrating Vector

\begin{tabular}{l|ll}
\hline & Ex ante & Ex post \\
\hline$q$ & 1.000 & 1.000 \\
$r$ & $0.019(2.256)$ & $0.015(1.670)$ \\
$r^{*}$ & $-0.043(-2.791)$ & $-0.040(-2.464)$ \\
$d 85 M 3$ & $0.031(0.364)$ & $0.070(0.805)$ \\
constant & $-4.549(-63.478)$ & $-4.570(-61.101)$ \\
\hline
\end{tabular}

Notes: Sample period 1973M1 to 2005M5. Lag lengths are determined by the Akaike Information Criterion. The $t$-statistics are in square brackets [.], and $d 85 M 3$ is a shift dummy which is zero before $1985 \mathrm{M} 3$ and one thereafter.

Table 7. ADF and Saikkonen and Lütkepohl Unit Root Tests

\begin{tabular}{|c|c|c|c|c|}
\hline & \multicolumn{2}{|c|}{ ADF } & \multicolumn{2}{|c|}{ S\&L } \\
\hline & $q$ & $r$ & $q$ & $r$ \\
\hline Austria & $-1.524(0)$ & $-2.067(11)$ & $-1.183(0)[1991 \mathrm{M} 3]$ & $-1.868(11)$ [1983M6] \\
\hline Belgium & $-1.756(0)$ & $-2.606(12)$ & $-1.495(0)[1991 \mathrm{M} 3]$ & $-1.573(12)[1984 \mathrm{M} 3]$ \\
\hline Canada & $-0.863(11)$ & $-3.169(11)^{*}$ & $-1.216(11)$ [1982M6] & $-2.716(11)[1980 \mathrm{M} 12]$ \\
\hline Finland & $-1.604(0)$ & $-1.299(11)$ & $-1.542(0)$ [1992M9] & $-1.668(11)$ [1983M12] \\
\hline France & $-1.653(0)$ & $-2.057(11)$ & $-1.677(0)[1982 \mathrm{M} 6]$ & $-2.455(11)[1982 \mathrm{M} 11]$ \\
\hline Germany & $-1.667(0)$ & $-2.764(11)$ & $-1.319(0)[1991 \mathrm{M} 3]$ & $-2.353(11)[1993 \mathrm{M} 1]$ \\
\hline Italy & $-1.675(1)$ & $-2.028(12)$ & $-1.340(0)$ [1992M9] & $-2.498(12)[1980 \mathrm{M} 2]$ \\
\hline Netherlands & $-1.864(0)$ & $-1.401(11)$ & $-1.555(0)[1991 \mathrm{M} 3]$ & $-1.449(11)[1987 \mathrm{M} 3]$ \\
\hline Norway & $-1.978(0)$ & $-1.546(12)$ & $-1.661(0)$ [1986M5] & $-1.065(11)[1993 \mathrm{M} 1]$ \\
\hline Spain & $-1.292(0)$ & $-3.095(12)^{*}$ & $-1.129(0)[1991 \mathrm{M} 3]$ & $-2.1846(12)[1986 \mathrm{M} 10]$ \\
\hline Sweden & $-1.641(1)$ & $-2.468(11)$ & $-1.428(1)$ [1992M11] & $-1.4919(11)$ [1991M3] \\
\hline \multirow[t]{2}{*}{ Switzerland } & $-1.706(0)$ & $-1.812(11)$ & $-1.647(0)$ [1978M11] & $-3.599(11)^{*}[1982 \mathrm{M} 11]$ \\
\hline & \multicolumn{2}{|c|}{$5 \%$ Critical Value $=-2.860$} & \multicolumn{2}{|c|}{$5 \%$ Critical Value $=-2.880$} \\
\hline
\end{tabular}

Notes: Sample period 1978M1 to 1998M12. Lag lengths in parentheses (.) are determined by the Akaike Information Criteria with a maximum of 12 lags. Significance at the five percent level is indicated by an asterisk (*). Asymptotic critical values at the five percent level for the ADF test are from Davidson and MacKinnon (1993). Critical values at the five percent level for the Saikkonen and Lütkepohl (2002) S\&L test are from Lanne et al. (2002). A constant is included in both the unit root tests. We use ex post interest rates. Shift Date is in square brackets [.]. 
Table 8. Johansen and S\&L Trace Test for Cointegration

\begin{tabular}{|l|c|c|c|c|c|}
\hline \multicolumn{1}{|c|}{ Null Hypothesis } & $H_{0}:$ rank=0 & $H_{0}:$ rank=1 & $H_{0}:$ rank=2 & Dummy & Lag \\
\hline Johansen Trace Test & & & & & \\
\hline Austria & $12.71[0.68]$ & $10.72[0.58]$ & $3.89[0.45]$ & -- & 12 \\
\hline Belgium & $197.38[0.00]$ & $77.32[0.00]$ & $3.31[0.53]$ & -- & 1 \\
\hline Canada & $32.28[0.09]$ & $7.65[0.85]$ & $0.95[0.94]$ & -- & 12 \\
\hline Finland & $43.13[0.00]$ & $18.83[0.08]$ & $6.28[0.18]$ & -- & 12 \\
\hline France & $40.48[0.01]$ & $18.89[0.08]$ & $4.79[0.32]$ & -- & 7 \\
\hline Germany & $195.27[0.00]$ & $79.22[0.00]$ & $2.82[0.62]$ & -- & 1 \\
\hline Italy & $36.29[0.04]$ & $14.57[0.26]$ & $5.61[0.20]$ & -- & 12 \\
\hline Netherlands & $20.52[0.69]$ & $10.46[0.60]$ & $3.15[0.56]$ & -- & 12 \\
\hline Norway & $40.84[0.01]$ & $17.76[0.11]$ & $5.30[0.26]$ & -- & 12 \\
\hline Spain & $32.47[0.09]$ & $16.03[0.17]$ & $4.56[0.35]$ & -- & 12 \\
\hline Sweden & $33.09[0.08]$ & $15.94[0.18]$ & $7.44[0.11]$ & -- & 10 \\
\hline Switzerland & $22.02[0.60]$ & $11.27[0.52]$ & $4.02[0.42]$ & -- & 10 \\
\hline & $12.14[0.70]$ & $2.42[0.91]$ & $2.07[0.18]$ & $1991 \mathrm{M} 3$ & 12 \\
\hline S\&L Trace Test & $17.56[0.28]$ & $8.89[0.18]$ & $3.98[0.05]$ & $1991 \mathrm{M} 3$ & 12 \\
\hline Austria & $41.82[0.00]$ & $29.75[0.00]$ & $2.57[0.13]$ & $1978 \mathrm{M} 11$ & 3 \\
\hline Netherlands & & & & & 12 \\
\hline Switzerland & & & & & 12 \\
\hline Notes: Sample perin| & & & & & 12 \\
\hline
\end{tabular}

Notes: Sample period 1973M1 to 2005M5. P-values are in square brackets [.] and are based on Trenkler (2004) which are in turn based on critical values for the Trace test from Saikkonen and Lütkepohl (2000). This test rejects the null hypothesis of rank $=i$ where the $p$-value is less than 0.05 . Lag lengths are determined by the Akaike Information Criterion with a maximum of 12 lags. A constant is also included in the cointegrating vector. 
Figure 1: Stability Test with the Ex Ante Interest Rates

A. Recursive eigenvalues

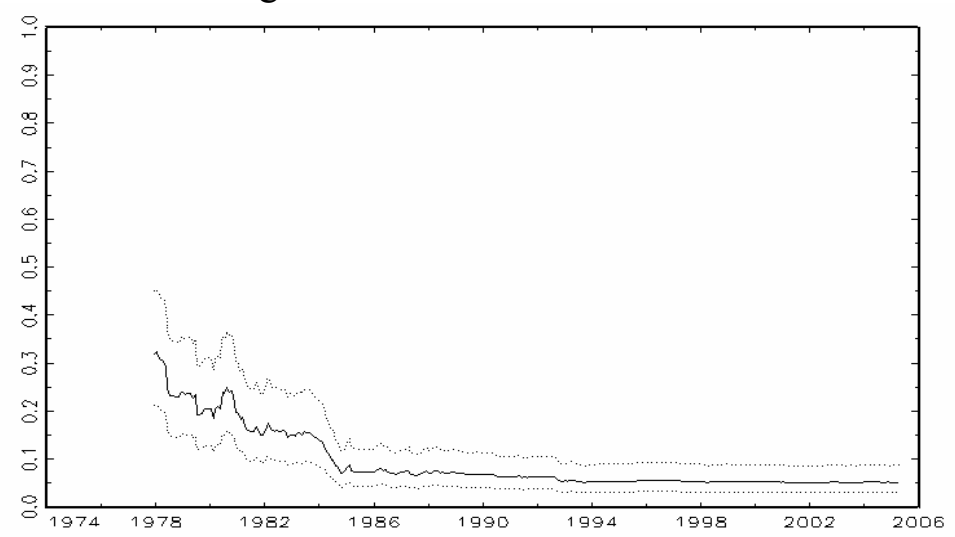

Figure 2: Stability Test with the $E x$ Post Interest Rates

A. Recursive eigenvalues

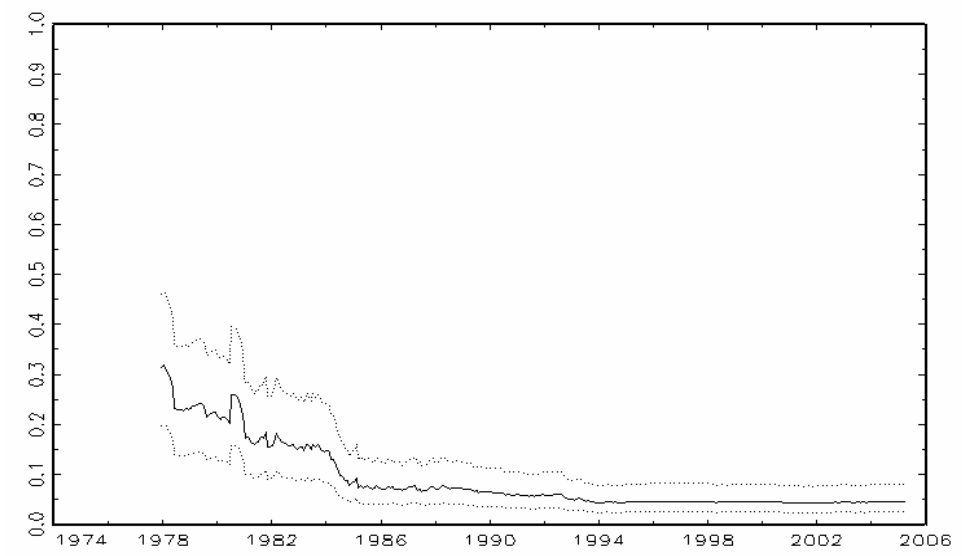

B. $\tau$-statistics

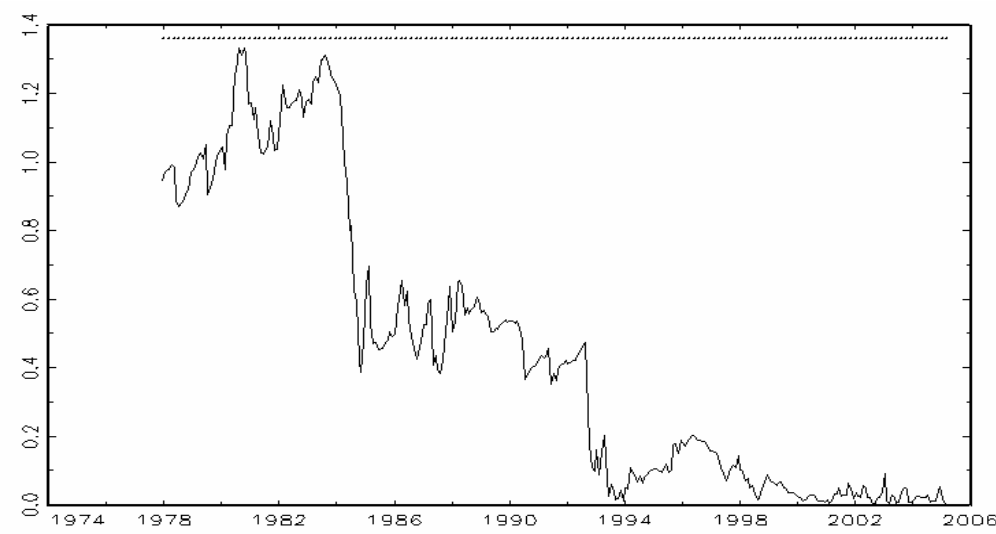

B. $\tau$-statistics

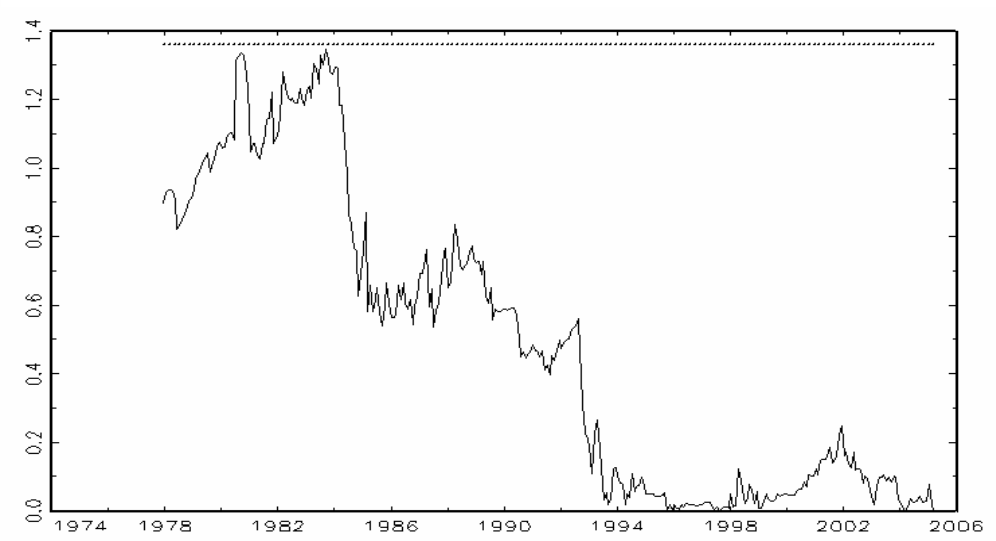

